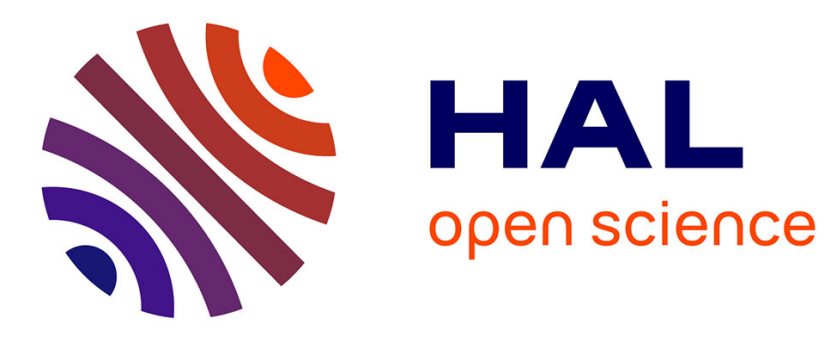

\title{
Modelling non-homogeneous flow and residence time distribution in a single-screw extruder by means of Markov chains
}

Denis Ponomarev, Élisabeth Rodier, Martial Sauceau, Clémence Nikitine, Vadim Mizonov, Jacques Fages

\section{To cite this version:}

Denis Ponomarev, Élisabeth Rodier, Martial Sauceau, Clémence Nikitine, Vadim Mizonov, et al.. Modelling non-homogeneous flow and residence time distribution in a single-screw extruder by means of Markov chains. Journal of Mathematical Chemistry, 2012, 50 (8), pp.2141-2154. 10.1007/s10910012-0022-x . hal-01618291

\section{HAL Id: hal-01618291 \\ https://hal.science/hal-01618291}

Submitted on 13 Dec 2017

HAL is a multi-disciplinary open access archive for the deposit and dissemination of scientific research documents, whether they are published or not. The documents may come from teaching and research institutions in France or abroad, or from public or private research centers.
L'archive ouverte pluridisciplinaire HAL, est destinée au dépôt et à la diffusion de documents scientifiques de niveau recherche, publiés ou non, émanant des établissements d'enseignement et de recherche français ou étrangers, des laboratoires publics ou privés. 


\title{
Modelling non-homogeneous flow and residence time distribution in a single-screw extruder by means of Markov chains
}

\author{
Denis Ponomarev • Elisabeth Rodier • \\ Martial Sauceau - Clémence Nikitine • \\ Vadim Mizonov • Jacques Fages
}

\begin{abstract}
Non-homogeneous velocity distribution of the flow in the channel of a single-screw extruder is taken into account by a new model developed on the basis of the Markov chains. This model allows calculating the Residence Time Distribution (RTD) as well as the influence of the operating conditions on the process at any velocity distribution in the channel. It has been used to represent experimental results on mass flow rate and RTD previously obtained by extrusion of an acrylic polymer, Eudragit E100, at different temperatures and screw rotation speeds. The diffusion coefficient is the only adjusting parameter of the model. It was shown that it does not depend on the screw rotation speed and a correlation between this diffusion coefficient and the barrel temperature was found. The model provides global understanding of the transport kinetics of the flowing material through the extruder according to its behaviour and better describes the progress of the polymer flow all along the barrel from the hopper to the die.
\end{abstract}

Keywords Extrusion - Mathematical modelling · Markov chain · Polymer processing $\cdot$ Residence time distribution

D. Ponomarev $\cdot$ E. Rodier $\cdot$ M. Sauceau $\cdot$ C. Nikitine $\cdot$ J. Fages $(\bigotimes)$ Ecole des Mines d'Albi, RAPSODEE Research Centre, CNRS, Université de Toulouse, 81013 Albi, France

e-mail: Jacques.Fages@mines-albi.fr

C. Nikitine

CPE-LGPC, UMR 2214, Université de Lyon, 69100 Villeurbanne, France

D. Ponomarev · V. Mizonov

Department of Applied Mathematics, Ivanovo State Power Engineering University, Rabfakovskaya 34, 153003 Ivanovo, Russia 


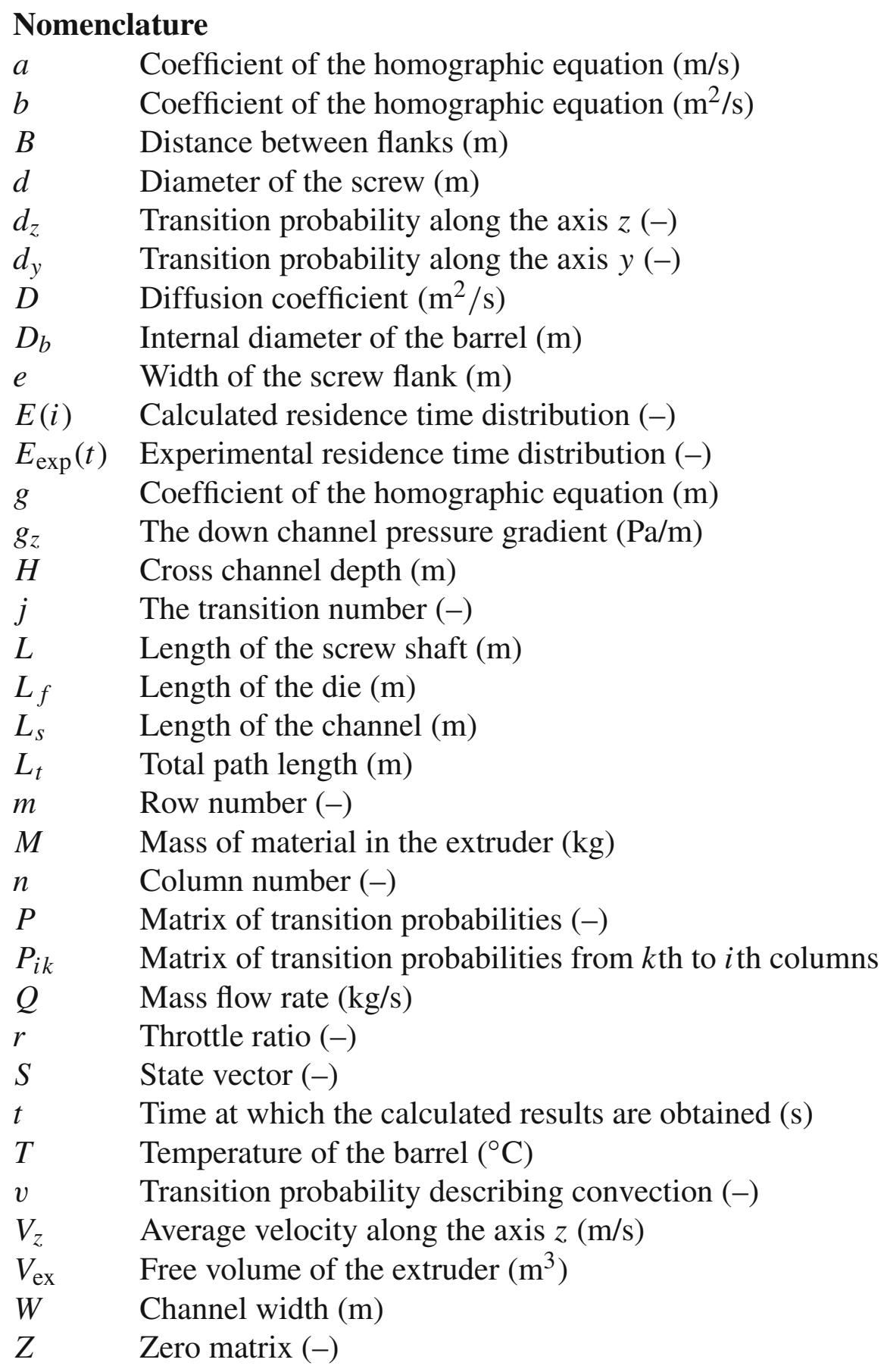

\section{Greek symbols}

$\Delta t \quad$ Time interval (s)

$\Delta t_{\exp } \quad$ Experimental time of sampling (s)

$\Delta y \quad$ Height of a cell (m)

$\Delta z \quad$ Length of a cell $(\mathrm{m})$

$\rho \quad$ Average density of the material $(\mathrm{kg} / \mathrm{s})$

$\mu \quad$ Viscosity (Pas) 


\section{Introduction}

Extrusion is a process for converting a raw material into a product of uniform shape and density by forcing it through a calibrated orifice called a die under controlled conditions [1]. Material transport is achieved by one or two Archimedes screws rotating inside a barrel, where pressure, produced by the rotating screw, forces material flow through the die. Industrial applications of the polymer extrusion process date back to the 1930s. It has been extensively applied in thermoplastic, food and rubber industries. Recently, extrusion has proved to be a promising manufacturing process for polymer foam production with the use of $\mathrm{CO}_{2}$ at supercritical conditions [2].

Several phenomena influence the characteristics of the final product and the global comprehension of extrusion is far from being reached [3]. Therefore, researches in this field can follow several directions $[4,5]$. One of them is the study of residence time distribution (RTD) of the matter under different operating conditions and its modelling in order to understand and better control the material flow along the extruder and through the die.

A research study on this subject has been described by Yeh and Jaw [6], and Singh and Rizvi [7], where a model based on the combination of continuous stirred tank reactors exchanging with stagnant zones and plug flow reactors in series was proposed. This approach deals with the classical partial differential equation (PDE) describing mass transport with dispersion-convection mechanisms. Dispersion mechanism occurrence depends on the process modelled. In the reactor modelling theory, different solutions of the PDE using Laplace transformation can be used. Convection and dispersion are characterised by respectively $v$, the bulk mean velocity and $D$, the dispersion coefficient. By considering $v=0$ and $D \neq 0$, an equation for a continuously stirred tank reactor can be obtained. On the contrary, if $D=0$ and $v \neq 0$, the equation applies to a plug flow reactor. Even if there is no analytical solution to this equation, this method allows fitting satisfactorily the experimental RTD data. However, models of this type bear some weaknesses. They cannot take into account extra phenomena without being drastically changed. They are difficult to apply when the dispersion and convection coefficients depend on concentration, temperature or pressure. In this case, it is necessary to get back to the original differential equations and to apply a numerical scheme to solve them.

More detailed research on polymer extrusion has been reported by Rauwendaal [1]. This author suggests that the velocity profile strongly depends on the phenomena occurring due to visco-elastic behaviour of the melt, pressure and temperature variations. The extruder is divided into several phenomenological zones: solid transport, melting (or metering) and pumping zones. The analysis is given on the velocity profile evolution in each zone according to the process characteristics and material properties. This approach remains very physical but requires sophisticated experimental work to determine the process coefficients.

In addition, possibilities of making experimental study on what happens inside the different zones of the extruder are often limited. Moreover, the rheological behaviour of polymers is usually non-Newtonian, which makes tough the study of their flowing features [8]. Most often, only integral process characteristics can be measured (for 
example, RTD, temperatures of the barrel and the matter in each zone, absolute value of material pressure in the zones and mass flow rate).

If a more detailed research on the process is required than the analytical solutions allow, it is necessary to develop numerical methods. Among them, a convenient approach for writing balance equations is based on cell models employing the theory of Markov chains $[9,10]$. One of its advantages is to make modelling processes in chemical engineering easier, because its matrix representation is straightforward to compute with a classic programming language. In addition, it allows a local description of the system by addressing in an explicit way the general case where the polymer velocity is not homogeneously distributed over the cross section of the screw channel. In most cases, this approach can be suitably linked with population balances, which mainly concern systems experiencing changes in time and space and that can be discretised as, for example, a flowing material along the screw of an extruder.

\section{Cell model of the extruder}

The basic structure of the single-screw extruder is described on Fig. 1. It consists of the barrel containing a rotating Archimedes' screw with a helical flight delimiting a channel of variable depth.

A hopper is placed at the inlet of the barrel to provide constant feed of material. A die of small diameter is located at the end of the extruder to shape the material upon exiting the extruder. Each zone of the barrel is surrounded by a heater to warm up the material. The raw material enters the extruder as granules, melts in the central part of the barrel and is eventually forced through the die by the screw [11].

The geometrical parameters of the extruder are given in Table 1 , where $L$ is the length of the screw and $L_{f}$ is the length of the die.

(a)

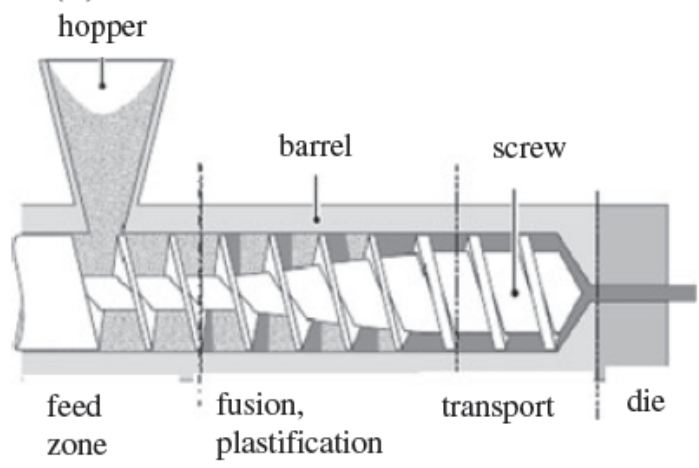

(b)

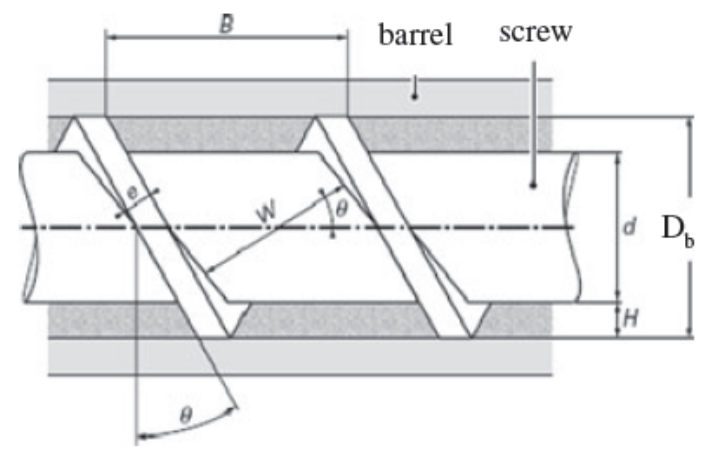

Fig. 1 Scheme of the extruder. a The extruder b Geometry of the screw (from [11])

Table 1 Geometry of the flow

\begin{tabular}{llllllll}
\hline$D_{b}(\mathrm{~m})$ & $d(\mathrm{~m})$ & $B(\mathrm{~m})$ & $e(\mathrm{~m})$ & $H(\mathrm{~m})$ & $\Theta\left({ }^{\circ}\right)$ & $L(\mathrm{~m})$ & $L_{f}(\mathrm{~m})$ \\
\hline $3 \times 10^{-2}$ & $2.7 \times 10^{-2}$ & $3 \times 10^{-2}$ & $3.5 \times 10^{-3}$ & $1.5 \times 10^{-3}$ & 17.66 & 1.0475 & $10^{-1}$ \\
\hline
\end{tabular}


Table 2 Geometry of the flow, additional parameters

\begin{tabular}{lll}
\hline Parameter & Equation & Value \\
\hline Width of the channel, $W(\mathrm{~m})$ & $B \cdot \cos (\Theta)-e$ & $2.5 \times 10^{-4}$ \\
Channel length, $L_{s}(\mathrm{~m})$ & $\frac{L \cdot \pi \cdot D_{b}}{B \cdot \cos (\Theta)}$ & 3.45 \\
Total path length (channel + die), $L_{t}(\mathrm{~m})$ & $L_{s}+L_{f}$ & 3.55 \\
\hline
\end{tabular}

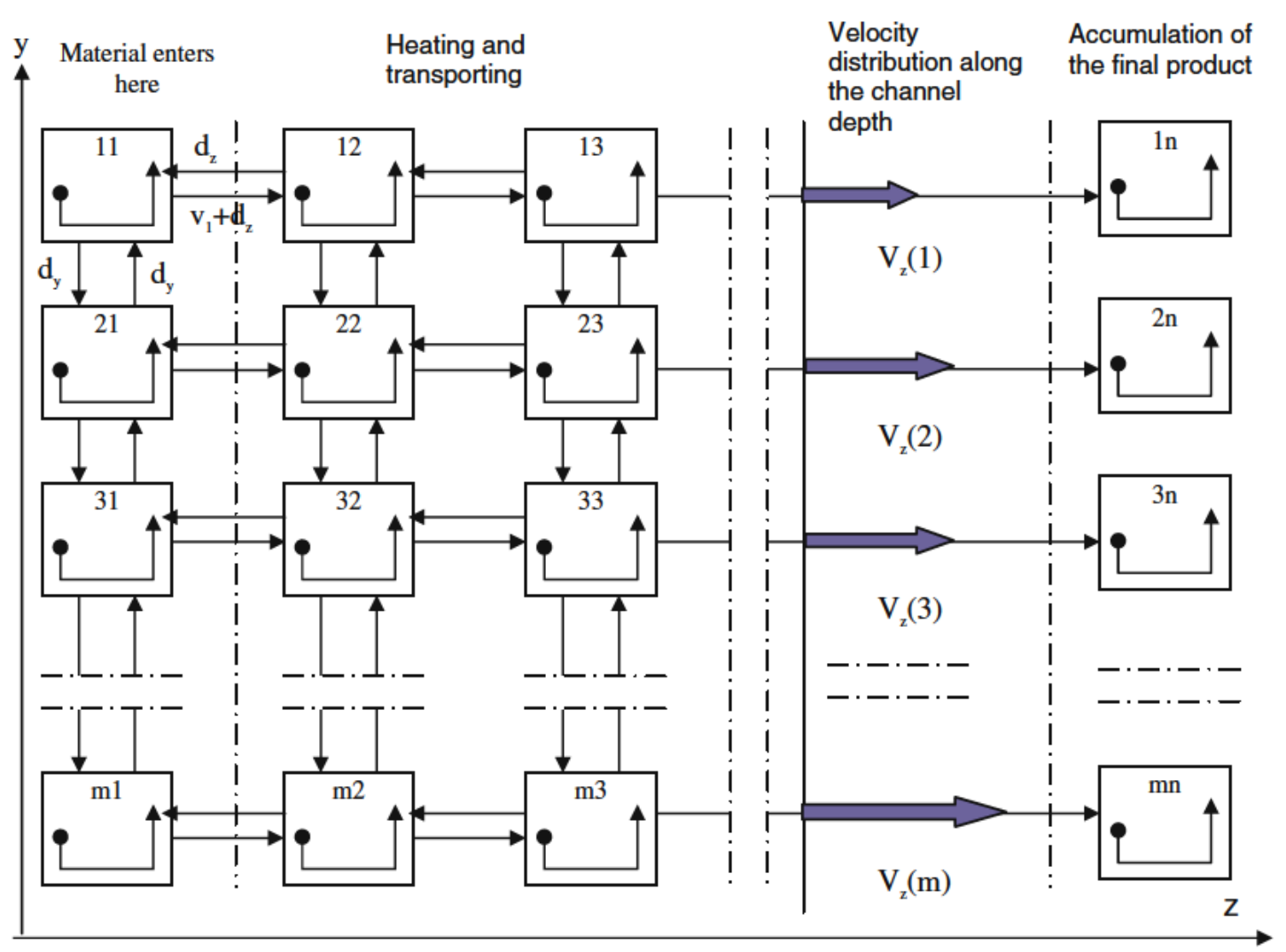

Fig. 2 2D cell space representing the kinetics of the flow

Some additional parameters of the experimental setup are given in Table 2.

For modelling purposes, the extruder volume is divided into a finite number of discrete intervals. The flow channel is represented as a two dimensional $[m, n]$ array of cells (see Fig. 2): $m$ index is for channel depth location ( $y$ axis) and $n$ is for axial location along the extruder between inlet and outlet ( $z$ axis).

The number of cells is taken as 18 in the horizontal direction $(n)$ and 5 in the vertical direction $(m)$. The number of cells can be higher depending on the level of accuracy required. The cell length is the channel length $L_{s}$ divided by $n$ and the cell width can be calculated as the channel height $H$ divided by $m$.

The last column of cells is an additional column that represents the product accumulation volume straight after the extruder outlet. As far as the velocities are different along the $y$ axis, it is supposed that each row of cells represents a flow with the average velocity $V_{z}(i)$ at $z$ axial location, $i$ being the number of the row in the vertical direction. Each cell location corresponds to a state of the system, which describes the 
Fig. 3 Transition probabilities in a cell (row from 2 to $m-1$ and column from 2 to $n-1)$



probability for a tracer to be in the corresponding cell. A set of the probabilities forms a state vector $S$, which has the size $[m n, 1]$ :

$$
S^{j}=\left[S_{1}^{j} S_{2}^{j} \ldots S_{m-1}^{j} S_{m}^{j} S_{m+1}^{j} \ldots S_{2 m}^{j} \ldots S_{n m-1}^{j} S_{n m}^{j}\right]^{t}
$$

where superscript $t$ means transposing a vector.

It is more convenient to number the cells like in Fig. 2 but, for further calculation, it is necessary to consider the state vector in Eq. (1), in which all the columns of the state matrix are placed one under another. What is the state of the process after a small interval of time $\Delta t$ called the transition duration? In this case, the discrete current time is:

$$
t=\Delta t \cdot(j-1)
$$

During the $j$ th transition the state vector changes and becomes $S^{j+1}$. The sequence of the state vectors is formed by the recurrent matrix equality:

$$
S^{j+1}=P S^{j}
$$

where $P$ is the matrix of transition probabilities of the size $(m \times n) \times(m \times n)$. Its general form is tridiagonal according to:

$$
P=\left[\begin{array}{llllll}
P_{11} & P_{12} & Z & \ldots Z & Z \\
P_{21} & P_{22} & P_{23} & \ldots Z & Z \\
Z & P_{32} & P_{33} & \ldots Z & Z \\
\ldots & \ldots & \ldots & \ldots & \ldots & \ldots \\
Z & Z & Z & \ldots & P_{m n-1, m n-1} & P_{m n-1, m n} \\
Z & Z & Z & \ldots & P_{m n, m n-1} & P_{m n, m n}
\end{array}\right]
$$

where $Z$ are zero matrices of the size $[m \times n], P_{i i}$ are the transition matrices inside $i$ th column, $P_{i k}$ are the matrices of transition probabilities from $k$ th to $i$ th columns.

We suppose that, during $\Delta t$, the transitions are allowed to the neighbouring cells only. In each direction, the probabilities of the transitions are not equal. They can be separated into a symmetric part that defines the pure diffusion and a non-symmetric part that defines the convection transfer or transport of material. This procedure is 
shown in Fig. 3. The probability to stay within a cell during a transition is equal to one minus the sum of the probabilities to leave the cell.

According to Fig. 2, the transition matrix $P_{11}$ can be written as:

$$
P_{11}=\left[\begin{array}{lllll}
1-d_{y}-d_{z}-v_{1} & d_{y} & 0 & \ldots 0 & 0 \\
d_{z}+v_{1} & 1-2 d_{y}-d_{z}-v_{2} & d y & \ldots 0 & 0 \\
0 & d_{z}+v_{2} & 1-2 d_{y}-d_{z}-v_{3} \ldots 0 & 0 \\
\ldots & \ldots & \ldots & \ldots \ldots & \ldots \\
0 & 0 & 0 & \ldots 1-2 d_{y}-d_{z}-v_{m-1} & d_{y} \\
0 & 0 & 0 & \ldots d_{z}+v_{m-1} & 1-d y-d z-v_{m}
\end{array}\right]
$$

The same principle is implied for building other matrices $P_{i i}$ in accordance with the scheme. The matrix of transition probability $P_{12}$ is:

$$
P_{12}=\left[\begin{array}{llllll}
d_{z} & 0 & 0 & \ldots & 0 & 0 \\
0 & d_{z} & 0 & \ldots & 0 & 0 \\
0 & 0 & d_{z} & \ldots & 0 & 0 \\
\ldots & \ldots & \ldots & \ldots & \ldots & \ldots \\
0 & 0 & 0 & \ldots & d_{z} & 0 \\
0 & 0 & 0 & \ldots & 0 & d_{z}
\end{array}\right]
$$

The other matrices are constructed using this method. The elements on the main diagonal of matrices $P_{i i}$ are calculated to keep the condition of normalisation, which requires that the sum of all probabilities in each column of the matrix $P$ should be 1. This approach is quite convenient but it is necessary to take care that no negative elements appear.

The velocity $V_{z}(y)$ is different along the channel depth, and we can assign certain value $V_{z}(i)$ to each row of the cells. In order to define the distribution of $V_{z}(i)$, the following homographic function is taken:

$$
V_{z}(y)=\frac{a \cdot y+b}{y+g}
$$

To determine the coefficients $a, b$ and $g$, any function can be used, according to the hydrodynamics theory for different flow regimes or experimental observations. The total mass flow rate can be defined as:

$$
Q=\rho \cdot W \cdot \int_{0}^{H} V z(y) \cdot d y
$$

where $\rho$ is the average density of the material obtained by the following equation:

$$
\rho=\frac{M}{V_{\mathrm{ex}}}
$$


Fig. 4 Discrete distribution of the velocity $V_{Z}$ in different rows

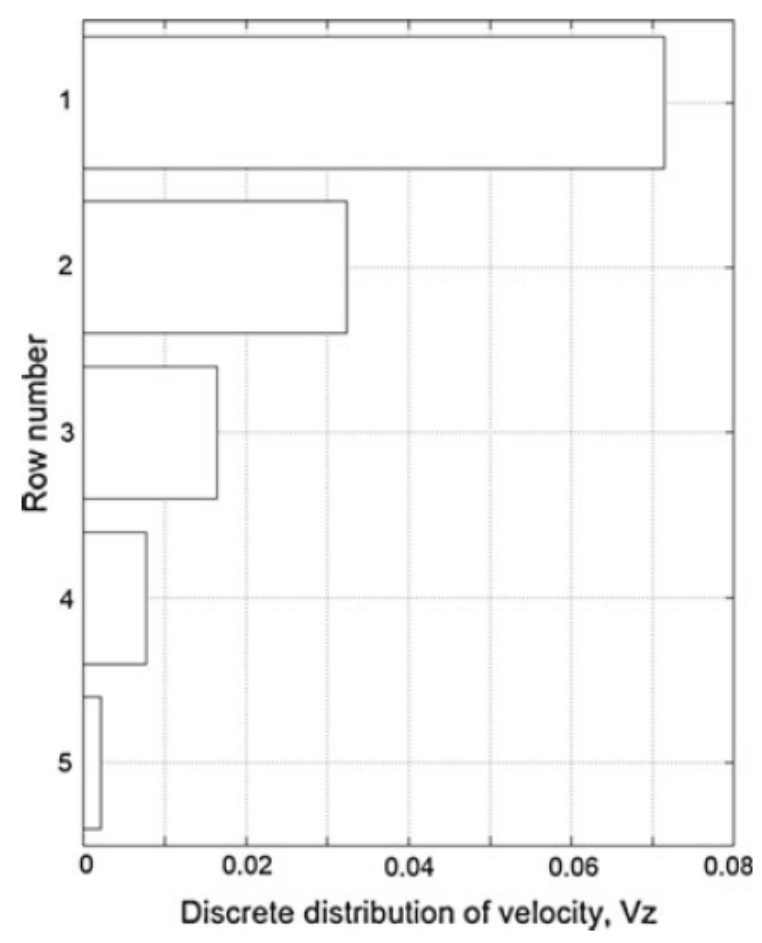

$M$ is the total mass of material inside the extruder and $V_{\mathrm{ex}}$ is its total free volume that is the maximum available volume for the material inside the extruder.

By substitution of (7) in (8), we can obtain the balance equation for the mass flow rate:

$$
Q=\rho W(a H+(b-a g) \ln ((H+g) / g))
$$

In order to find the values of the coefficients $a, b$ and $g$, the boundary conditions:

$V_{z}(0)=w r, V_{\mathrm{z}}(h)=0$ and the balance Eq. (10) can be used.

Once the coefficients are found, a continuous function of velocity distribution can be used over the depth of the channel. To apply this function to the Markov chain model, we need the average values of the velocity for each cell according to the mean value theorem. An example of the discrete distribution of the velocity in rows is shown in Fig. 4.

This interval is determined by the cell height:

$$
\Delta y=\frac{H}{m}
$$

The cell length is different from its height. It can be calculated by:

$$
\Delta z=\frac{1}{n-1} \cdot\left(\frac{\pi \cdot D}{\cos (\Theta)} \cdot \frac{L}{B}+L f\right)
$$

The average velocity $V_{z}(i)$ in the row $i$ is the basis for a transition probability $v_{i}$, which has to be defined before modelling the process. The forward transition probability $v_{i}$ can then be written as: 


$$
v_{i}=V_{z}(i) \frac{\Delta t}{\Delta z}
$$

According to the Fick's first law, the relative part of mass transported by diffusion from one cell to another can be written for the corresponding axis as:

$$
\begin{aligned}
& d_{z}=D \frac{\Delta t}{\Delta z^{2}} \\
& d_{y}=D \frac{\Delta t}{\Delta y^{2}}
\end{aligned}
$$

where $D$ is the diffusion coefficient of the tracer into the polymer. We consider an isotropic diffusion, therefore $D$ has the same value in both directions $z$ and $y$.

The outflow can be calculated as a difference between the sum of states in the last column after $j$ and $j+1$ transitions, according to:

$$
E(j)=\sum_{m(n-1)+1}^{m n}\left(S_{k}^{j+1}-S_{k}^{j}\right)
$$

Having the RTD, the mean residence time and variance can be easily calculated.

However, the set of data obtained from Eq. (16) must be adjusted to the set of experimental data. Usually, the calculation procedure gives the mass outflow after each transition time, $\Delta t$. The experimental curve gives the mass outflowing per time interval $\Delta t_{\exp }$ (the time of collecting a sample), which is not equal to $\Delta t$. Thus, the results cannot be compared directly and it is necessary to transform them to an identical time step.

\section{Results and discussion}

\subsection{Experiments}

The methods of experimentation as well as the experimental set up have been described in details by Nikitine et al. [12]. The polymer used for these experiments was Eudragit E100. First, the granules of polymer were introduced into the extruder hopper. As soon as a steady state regime was established, mean polymer mass flow rate and filling rate were measured by a mass balance. Then, a peak injection of a coloured tracer, erythrosine, was done at the inlet of the extruder. Then, the polymer flowing out at the die was cooled and cut every 10 s until the tracer disappearance. Afterwards, the samples obtained were dissolved in ethanol and the tracer concentration was determined by an UV-spectrophotometer. These experiments were made at different temperatures and screw rotation speeds.

\subsection{Mass flow rate and velocity distribution in the channel}

The first experimental results were obtained on the mass flow rate [12]. The total mass of polymer Eudragit E100 inside the extruder was $0.126 \mathrm{~kg}$. The experiments on the 
Table 3 Model parameters and characteristics (experiments with the die of $3 \mathrm{~mm}$ in diameter)

\begin{tabular}{lllllll}
\hline $\begin{array}{l}\text { Parameters of } \\
\text { the model }\end{array}$ & $\begin{array}{l}130^{\circ} \mathrm{C}, \\
20 \mathrm{rpm}\end{array}$ & $\begin{array}{l}130^{\circ} \mathrm{C}, \\
40 \mathrm{rpm}\end{array}$ & $\begin{array}{l}130^{\circ} \mathrm{C}, \\
60 \mathrm{rpm}\end{array}$ & $\begin{array}{l}130^{\circ} \mathrm{C}, \\
80 \mathrm{rpm}\end{array}$ & $\begin{array}{l}140^{\circ} \mathrm{C}, \\
40 \mathrm{rpm}\end{array}$ & $\begin{array}{l}150^{\circ} \mathrm{C}, \\
40 \mathrm{rpm}\end{array}$ \\
\hline $\begin{array}{l}D\left(\mathrm{~m}^{2} \mathrm{~s}\right. \\
\text {-1) }\end{array}$ & $10^{-10}$ & $10^{-10}$ & $10^{-10}$ & $10^{-10}$ & $3.5 \times 10^{-10}$ & $4.5 \times 10^{-10}$ \\
$\begin{array}{l}\text { Characteristics } \\
\text { Measured mass } \\
\text { low rate } Q(\mathrm{~kg} / \mathrm{s})\end{array}$ & $4.6 \times 10^{-4}$ & $7.29 \times 10^{-4}$ & $1.1 \times 10^{-3}$ & $1.48 \times 10^{-3}$ & $9.66 \times 10^{-4}$ & $1.25 \times 10^{-3}$ \\
$\begin{array}{l}\text { Mean time }(M / Q)(\mathrm{s}) \\
2\end{array}$ & $2.74 \times 10^{2}$ & $1.73 \times 10^{2}$ & $1.15 \times 10^{2}$ & $0.85 \times 10^{2}$ & $1.3 \times 10^{2}$ & $1.01 \times 10^{2}$ \\
$\begin{array}{l}\text { Experimental } \\
\text { mean time (s) }\end{array}$ & $2.46 \times 10^{2}$ & $1.83 \times 10^{2}$ & $1.22 \times 10^{2}$ & $0.89 \times 10^{2}$ & $1.32 \times 10^{2}$ & $1.01 \times 10^{2}$ \\
$\begin{array}{l}\text { Calculated } \\
\text { variance }(-)\end{array}$ & 0.1453 & 0.1792 & 0.1511 & 0.1245 & 0.2886 & 0.2245 \\
$\begin{array}{l}\text { Experimental } \\
\text { variance }(-)\end{array}$ & 0.1519 & 0.1599 & 0.1545 & 0.1421 & 0.2283 & 0.1845 \\
\hline
\end{tabular}

mass flow at different temperatures and different screw rotation speeds are shown in Table 3. When the rotation speed or barrel temperature increased, the mass flow rate also increased, as expected. The viscosity of the polymer decreases at higher temperatures, which results in an enhanced mass flow rate. Higher rotation speed of the screw causes higher pressure gradients that also increase the mass flow rate. Knowing the total mass of material and the free internal volume of the extruder, $169.1 \mathrm{~cm}^{3}$, we could calculate the density of material, which is $745.08 \mathrm{~kg} / \mathrm{m}^{3}$. The velocity distribution in Eq. (7) with its mean values on the intervals, is calculated from the coefficients determination according to Eq. (10) and to the boundary conditions mentioned earlier.

In addition, Rauwendaal [1] derived the coefficient $r$ (throttle ratio) showing the influence of the process parameters on the velocity distribution of the conveying or pumping zone in the extruder:

$$
r=\frac{H^{2}}{6 \mu V_{z}}
$$

This ratio $r$ compares the importance of the backward "Poiseuille" axial flow due to the pressure gradient to the forward shear flow due to velocity $V_{z}$. It means that, for instance for $r=1 / 3$, the forward flow is predominant all over the height of the channel and, for $r=2 / 3$, some backward flow is present near the screw while a forward flow exists near the barrel. This ratio may enlighten the relationships between flow characteristics. It comes from the model that $r$ decreases with temperature, that may result from the fact that the down channel pressure gradient $g_{z}$ decreases faster than the shear flow $\left(\mu, V_{z}\right)$.

\subsection{Influence of the barrel temperature on RTD}

Experimental residence time distribution can be represented using the following equation:

$$
\Delta E_{\exp }(t)=\frac{\Delta M_{j}}{\sum_{j} \Delta M_{j}} .
$$



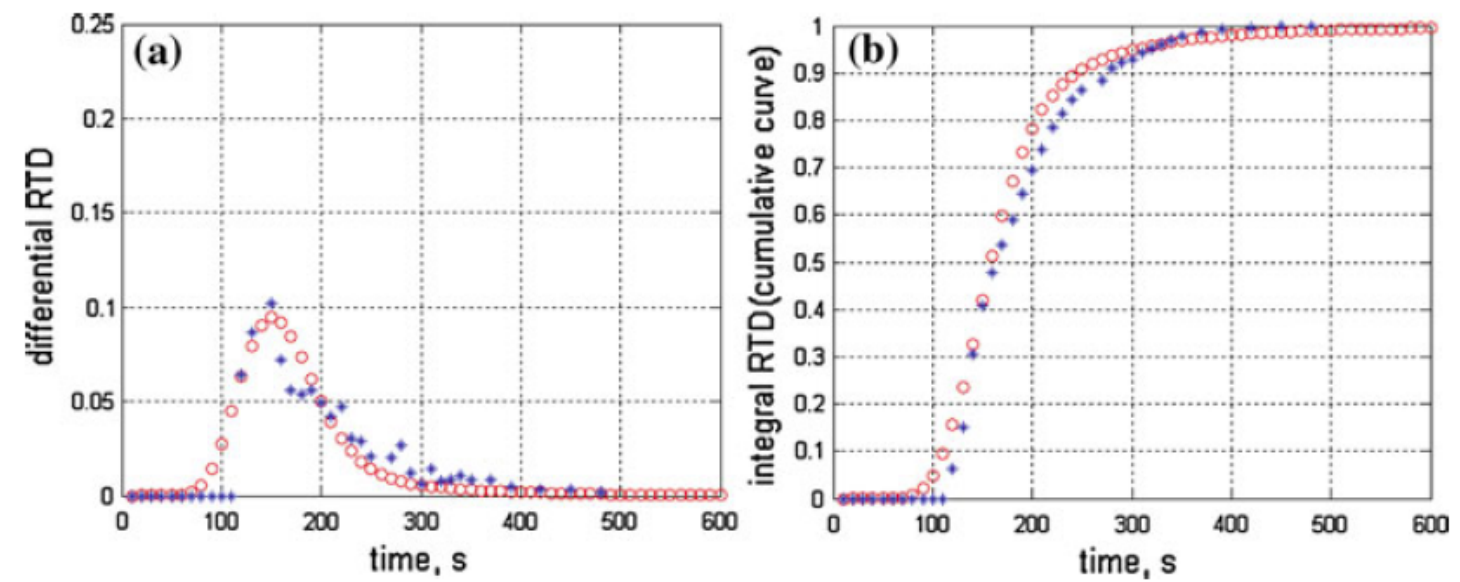

Fig. 5 RTD at $40 \mathrm{rpm}$ and $130^{\circ} \mathrm{C}$. a Differential curve, b cumulative curve
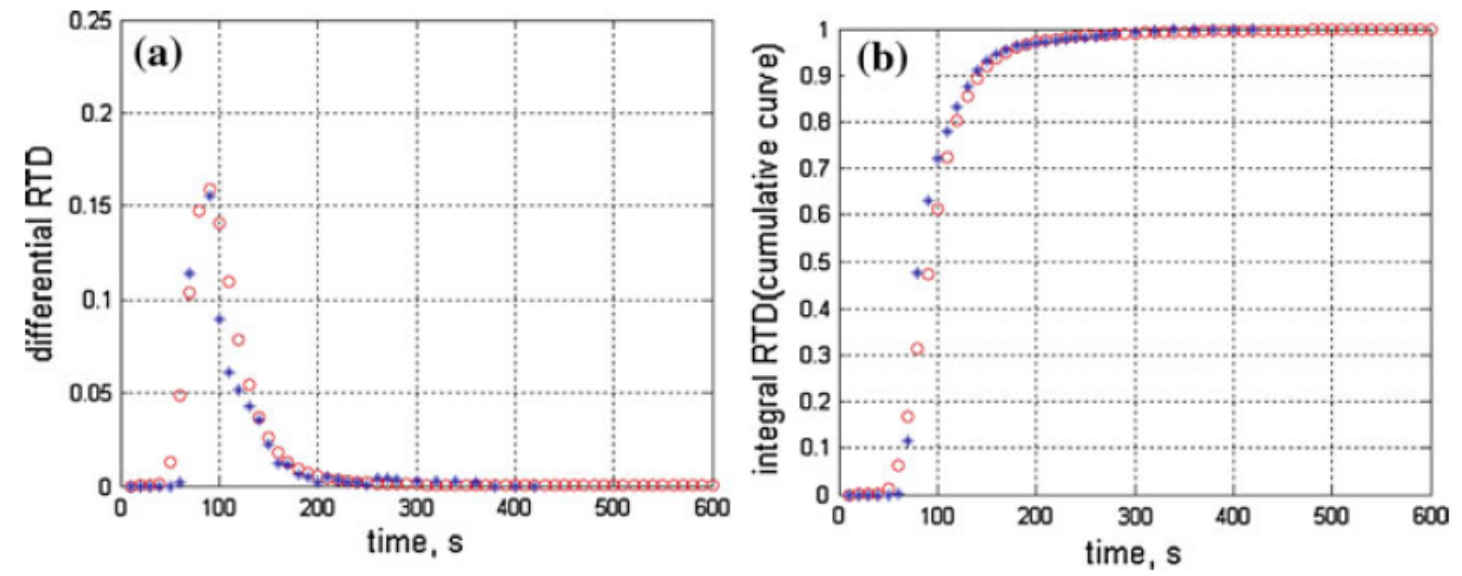

Fig. 6 RTD at $40 \mathrm{rpm}$ and $140^{\circ} \mathrm{C}$. a Differential curve, b cumulative curve
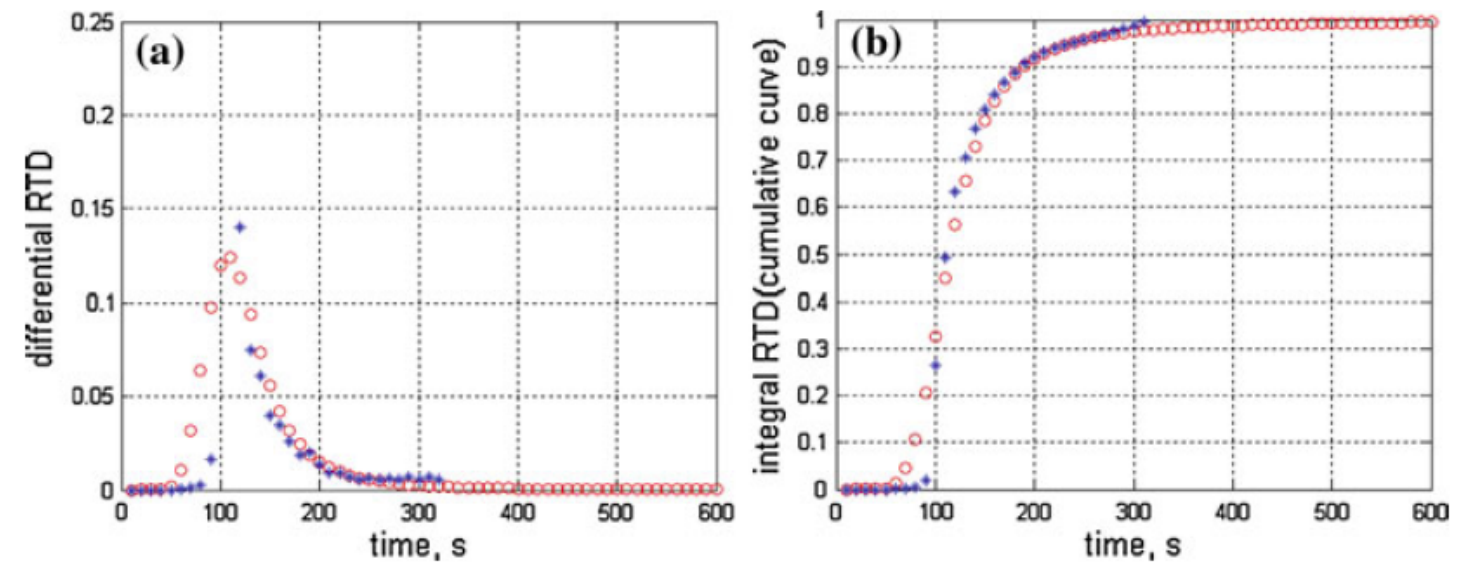

Fig. 7 RTD at $40 \mathrm{rpm}$ and $150^{\circ} \mathrm{C}$. a Differential curve, b cumulative curve

where $\Delta M_{j}$ is the tracer mass in the $j$ th sample.

The RTD characteristics are shown in Figs. 5, 6 and 7 for the screw speed of $40 \mathrm{rpm}$ at 130,140 and $150^{\circ} \mathrm{C}$ respectively. The star symbols are used to represent the experimental data and the open symbols represent the calculated results. As far as the model 
Fig. 8 Diffusion coefficient versus temperature at the rotation speed of $40 \mathrm{rpm}$

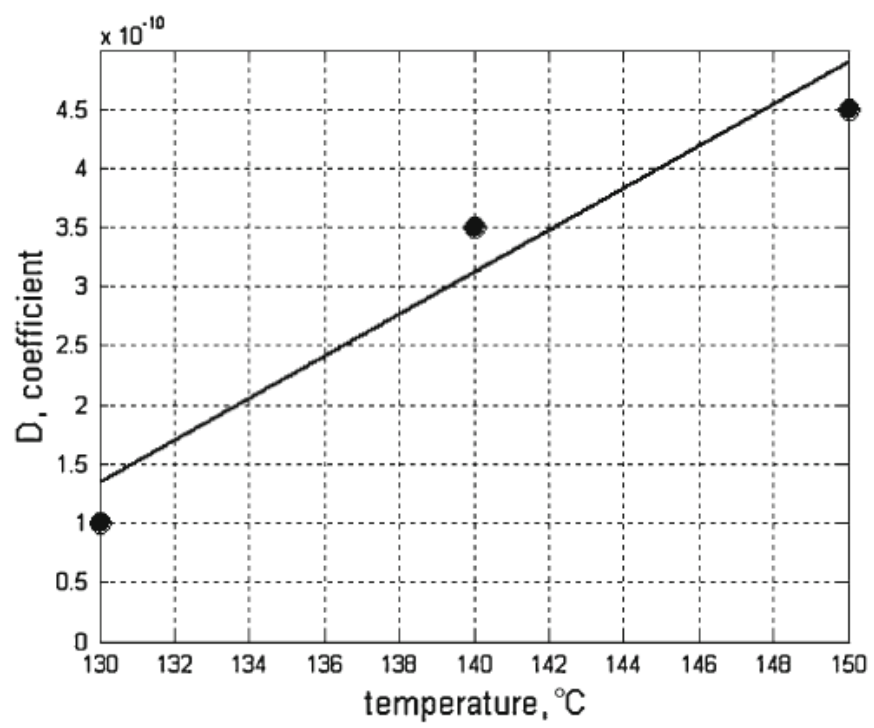

(b)

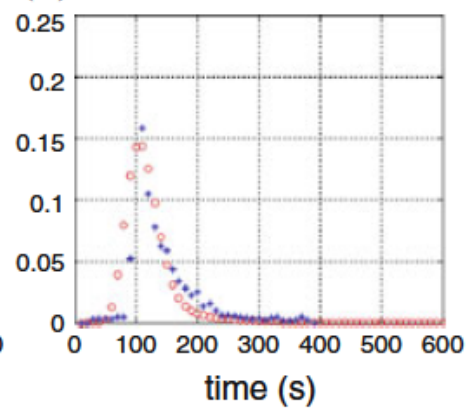

(c)

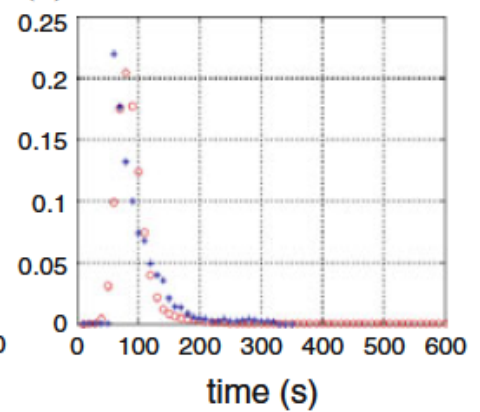

Fig. 9 RTD at $130^{\circ} \mathrm{C}$ for different screw rotation speed. a $20 \mathrm{rpm}$, b $60 \mathrm{rpm}$, c $80 \mathrm{rpm}$

has one adjusting parameter, which is the diffusion coefficient $D$, the least square method was used.

The values of calculated parameters and characteristics are given in Table 3 . The mean residence time decreases at higher temperature, viscosity also decreases resulting in an enhanced mass flow rate. The values of $D$ are $10^{-10}, 3.5 \times 10^{-10}$ and $4.5 \times 10^{-10} \mathrm{~m}^{2} \mathrm{~s}^{-1}$ for the temperatures 130,140 and $150^{\circ} \mathrm{C}$ respectively (see Fig. 8).

These values seem to be correlated to temperature values. Interpolated by a linear function, these points follow:

$$
D(T)=1.75 \times 10^{-11} T-21.35 \times 10^{-10}
$$

where $130{ }^{\circ} \mathrm{C} \leq T \leq 150^{\circ} \mathrm{C}$. The polymer viscosity decreases with temperature, which results in higher values of the diffusion coefficient $D$. This suggests an enhanced plug flow and this is consistent with the interpretation of the same experimental curves as a combined continuous stirred tank reactor exchanging with stagnant zones and plug flow reactor in series [12]. 


\subsection{Influence of the screw rotation speed on RTD}

Several RTD characteristics are shown in Fig. 9 for the temperature $130^{\circ} \mathrm{C}$ at 20,60 and $80 \mathrm{rpm}$ respectively. The values of calculated parameters and characteristics are given in Table 3 . It was found that the diffusion coefficient $D$ hardly depends on the rotation speed of the screw.

The evolution of the throttle ratio $r$ in Eq. (17) is not so straight. Indeed, calculations show two opposite tendencies with the increase of the screw rotation speed: the down channel pressure gradient $g_{z}$ increases and the viscosity $\mu$ diminishes (due to higher shear rates), which suggests that the Poiseuille backward flow increases, while the down channel velocity $V_{z}$ increases.

The values of the mean residence time are the consequences of what has been mentioned above: the increase in the screw rotation speed enhances mass flow rate and decreases viscosity (with higher shear rates) thus decreasing the mean residence time.

\section{Conclusion and perspectives}

Non-homogeneous crosswise velocity profile distribution of the flow in a single screw extruder has been taken into account by a new model developed on the basis of Markov chains. The volume of the extruder was represented as a two dimensional array of cells exchanging material mass with their neighbours. The model describes the transport of polymeric material along a horizontal extruder barrel and allows calculating concentration and RTD at its outlet. The main feature of the model developed allows to link the transition probabilities with the physics of the process and, thus, the approach becomes more physical. The model can be also used to predict RTD characteristics within the experimental conditions domain without making additional experiments. Velocity distribution is closely related to the rheological properties of the material. Therefore, by knowing how changes in rheological properties may modify the velocity distribution, it becomes possible to study how the flow characteristics change.

The diffusion coefficient $D$ is the only adjusting parameter of the model. It appeared that $D$ does not depend on the screw rotation speed. An empirical correlation of $D$ versus temperature was obtained. The model developed can potentially be applied to other flow processes where the velocity distribution is not homogeneous or where a backward flow may occur.

As prospect, the velocity distribution in different zones could be very interesting to measure. Modelling the heat exchange and phase transformations [13] is another track for the model development. This would require though a more sophisticated experimental set up to measure additional characteristics of the process.

Acknowledgments Authors acknowledge the financial support of the program GEMBIO from the Groupe des Ecoles des Mines (France).

\section{References}

1. C. Rauwendaal, Polymer Extrusion, 4th edn (Hanser Publishers, München, 2001)

2. M. Sauceau, J. Fages, A. Common, C. Nikitine, E. Rodier, Prog. Polym. Sci. 36, 749 (2011)

3. S.-T. Lee, Foam Extrusion. Principles and Practice (CRC press, Boca Raton, 2000) 
4. M. Sauceau, C. Nikitine, E. Rodier, J. Fages, J. Supercrit. Fluids 43, 367 (2007)

5. C. Nikitine, E. Rodier, M. Sauceau, J.-J. Letourneau, J. Fages, J. Appl. Polym. Sci. 115, 981 (2010)

6. A.-I. Yeh, Y.-M. Jaw, J. Food Eng. 35, 211 (1998)

7. B. Singh, S.H. Rizvi, J. Food Process Eng. 21, 91 (1998)

8. S.C. Kazarian, Polym. Sci. 42, 78 (2000)

9. A. Tamir, Applications of Markov chains in Chemical Engineering (Elsevier Science Publisher, Amsterdam, 1998)

10. H. Berthiaux, V. Mizonov, Can. J. Chem. Eng. 6, 143 (2004)

11. B. Vergnes, S. Puissant, in Techniques de l'Ingénieur, traité Plastiques et Composites AM 3650 , pp. 1-16 (2002)

12. C. Nikitine, E. Rodier, M. Sauceau, J. Fages, Chem. Eng. Res. Des. 87, 809 (2009)

13. V. Mizonov, H. Berthiaux, P. Arlabosse, D. Djerroud, Granul. Matter 10, 335 (2008) 